\title{
A CIDADE, A FESTA E A CULTURA POPULAR
}

\author{
Nelson da Nobrega Fernandes \\ Universidade Federal Fluminense
}

A cidade e a festa são elementos primordiais e permanentes da civilização, porque nelas os homens se encontram e alcançam os mais altos níveis de cooperação, criação, solidariedade e sociabilidade. Geralmente, essa origem comum da cidade e da festa é pouco percebida por mentes racionalistas e pragmáticas, que tendem a tratar as cidades rituais e festivas como uma exceção. Assim, quando temos que explicar as origens das cidades, prendemo-nos às razões ou causas de natureza econômica, política e geográfica, o que não está errado na maior parte dos casos. Contudo, quando pensamos nos sentidos mais profundos para a cidade, podemos dizer que os homens construíram-na para fazer seus rituais e festas. Esta é a primeira lição que Mumford (1982) nos dá em sua obra monumental "A cidade na história".

Mumford mostra que a "cidade" primitiva era formada por sítios rituais e míticos, nos quais, de tempos em tempos, os grupos de coletores e caçadores retornavam para a celebração de seus deuses e antepassados. Cavernas, cemitérios, morros e outros sítios formam as primeiras cidades. Assim, muito antes que a cidade se tornasse um fixo, ela foi um ponto de encontros periódicos. A cidade é imã e recipiente - atrai e abriga os homens -, mas a função de imã precede a de receptáculo.

A origem ritual da cidade cresce diante de nossos olhos, na paisagem, quando observamos que os mortos foram os primeiros a terem o direito e privilégio de uma residência fixa em um lugar comum. Os cemitérios, as necrópoles, foram as primeiras cidades. Por essas e outras razões, para Mumford as festas e os rituais são "um dos critérios essenciais da cidade", fizeram as cidades emergir e com elas permaneceram por toda a sua longa história. Acima de tudo, o mais intenso momento de identidade e transcendência que pode ocorrer na vida cívica de uma comunidade acontece no transcurso de suas celebrações e festas populares. Apesar 
disso, só muito recentemente a geografia passou a prestar atenção nestes fenômenos culturais na construção e desenvolvimento do espaço e da vida urbana.

No final dos anos 80 Claval (1987) afirmou que durante muito tempo persistiu entre os geógrafos a dúvida quanto às suas possibilidades de cuidar de questões relativas ao imaginário, ao simbólico e ao imaterial. Tudo isto estava muito longe "dos fatos tangíveis e da paisagem", era muito estranho tratar dessas questões, "mesmo quando se sentiram obrigados a referir-se a elas". Nestas circunstâncias e "quando se arriscavam por estes caminhos", os geógrafos o faziam ocultando-se, "como pedindo perdão"; entravam nesse campo como penetras mal disfarçados numa festa, tratavam desses assuntos de forma obrigatória, o mais ligeiro possível e sem aprofundamentos, pois sobre eles, "não era conveniente se estender, como fizeram Pierre Defontaines em, 'Geografia e religião', e Xavier de Planhol, em ‘A geografia do Islã'".

Em "O estudo geográfico das cidades" - considerado o trabalho fundador da geografia urbana no Brasil - Monbeig (1943) afirmou esta orientação guiada pelo princípio de uma divisão rígida entre as ciências, em que cada uma deveria cuidar de seu objeto e não invadir territórios alheios. Assuntos como a religião e seus rituais estavam muito além do espaço concreto do geógrafo e deveriam ser tratados por sociólogos e antropólogos. No seu julgamento, "tais fenômenos necessitam, para ser explicados, de métodos de pesquisas e hábitos de pensamento que o geógrafo não possui. Assim, as técnicas científicas constituem uma barreira automática, exceto para os presunçosos, que não hesitarão em transpô-la" (MONBEIG, op. cit.: 9).

Hoje a situação é diferente, como geógrafos já não temos que pedir perdão para tratar de temas como a cidade, o carnaval carioca e a identidade nacional, como fiz com as Escolas de Samba do Rio de Janeiro (FERNANDES: 2001). A valorização destes problemas na cultura pós-moderna, ao lado dos esforços de revisão critica do pensamento geográfico nas duas últimas décadas autorizam a investigação de problemas como normas, valores e o imaginário social, não mais como objetos externos e proibidos. Mais importante ainda é recordar que a geografia nunca esteve afastada dos debates sobre a cultura; não é, portanto, surpreendente que encontremos nas diversas escolas geográficas alguma teoria sobre a cultura, mesmo que de forma subjacente ou pouco explícita. Afinal de contas, a noção de gênero de vida é uma categoria da cultura.

Meu estudo sobre as escolas de samba está situado dentro desse campo de renovação da geografia cultural, constituído por novos temas e questões da ciência e do pensamento social contemporâneo. Contudo, não sou o pioneiro a tratar desse assunto, pois, na década de 1940, o Carnaval carioca, especialmente o samba, foram abordados por Alberto Lamego em "O homem e a Guanabara", obra dividida em três partes: o homem, o meio e a cultura. Ali se constrói uma descrição que, começando pela geologia, culmina por eleger o samba como uma "síntese geo-sentimental" do espírito carioca, quer dizer, segundo aquele autor, a dança do samba, 
os passos, a sinuosidade e os volteios de seus passistas apenas projetavam na cultura o sítio da cidade e seus geossinclinais.

Numa breve análise sobre as razões de um geógrafo determinista se interessar pelo samba (FERNANDES: 1999), observei que este é um exemplo em que intérpretes racionalistas se ocupam de temas populares, que muitas vezes são vistos como uma espécie de patrimônio das mentes românticas. Tudo indica que o samba naquela época foi um tema tão relevante, como mostrou Hermano Viana em o "Mistério do Samba", que fez um determinista a ele recorrer para concluir seu estudo sobre o Rio de Janeiro, exemplificando uma situação em que a geografia aparece claramente conectada ao debate contemporâneo. Ao culminar sua obra com o samba Lamego atualizou seu discurso determinista, sintonizando-o com temas como a miscigenação e a identidade cultural nacional, que continuavam mais que nunca na ordem do dia do pensamento social brasileiro dos anos 40 . Aliás, Lamego não exibe qualquer atitude perante a cultura que revele desconforto, culpa ou medo por estar num terreno tão exótico ao geógrafo, sugerindo que aquela espessa tradição mostrada por Claval e que proibia certos temas aos geógrafos nem sempre foi um dogma intransponível. De qualquer forma, a partir de Capel (1981) se compreende que dentro da divisão do trabalho científico, tanto as conjunturas epistemólogicas quanto as estratégias de reprodução científica e institucionais fizeram com que os geógrafos evitassem a cultura imaterial, o simbólico e a ideologia em seus estudos na maior parte do século XX; pois não tratar de certos temas, privilegiar outros, com teorias explícitas ou implícitas, é sempre uma forma de se estabelecer identidade, definir campo de trabalho e ganhar legitimidade perante as outras disciplinas.

Deixando de lado a geografia com seus limites e possibilidades no trato dos temas culturais, retornemos à festa como um critério essencial da cidade. Vemos em Bakhtin (1971:14) que a festa, tal como a cidade, é uma forma primordial da civilização e por isso não se pode explicá-las segundo princípios pragmáticos. De fato, somente a lógica da acumulação burguesa e capitalista pode confundir festa com descanso do trabalho. Para entender Bakhtin basta recordarmos dos às vezes aborrecidos e entediantes domingos. Muito menos se pode reduzir a festa à lógica do pão e circo, ou seja, como instrumento de manipulação das massas ignorantes e alienadas.

Na realidade, a festa é uma das mais profundas e permanentes necessidades da sociedade humana, pois é instrumento daqueles ideais de toda a civilização, quer dizer, o tempo e o lugar onde se promove o céu na terra, a vida ideal do povo, a vida mesma al revés. A festa é, ou pelo menos deve ser, o tempo da boa comida, da ironia, do cômico, da abolição provisória de todas as hierarquias, artificialismos e limitações que separam os homens na vida ordinária e cotidiana. Por isso, para que haja festa, são necessários elementos do espírito, de transcendência, "do mundo das idéias e dos ideais". Eles devem preponderar para que se alcance o clima de festa. 
A festa, segundo Maquard (1998:359), é uma moratória do cotidiano e atitude exclusiva do homem. Nenhum outro ser é capaz da festa, em geral todos anseiam por seu tempo, embora existam aqueles que dela não gostam e com ela evitam ter maiores envolvimentos. Mas, mesmo estes, não podem sempre contornar as obrigações sociais rituais e festivas, casamentos, batizados, datas cívicas, festas populares, religiosas, desportivas etc. Diz este autor:

O homem é um ser excêntrico entre os seres vivos. Todos os demais vivem as suas vidas, enquanto o homem adota um comportamento em relação a ela, coisa que só é possível porque toma distância em relação a sua vida. Ao homem compete sempre estas duas atitudes: viver sua vida e distanciar-se dela. Por isso - precisamente por sua excentricidade - o homem necessita a festa.

Ao tratar desse assunto Calvo (1991) apontou que a festa, tal como o jogo, é uma atividade lúdica. Mas esta ultima não é exclusiva ao homem: os animais jogam e brincam, além do que podemos jogar de modo solitário. Ao contrário, não se pode fazer festa sozinho. A menor, mais íntima e privada festa que se pode fazer tem que ser em dupla, porque "ninguém pode ser público de si mesmo, posto que resulta impossível se contemplar com a expectação surpreendida". Diferentemente do jogo, a festa requer, como condição necessária, um público espectador que participa da celebração.

Fazer festa é transformar a vida social em vida pública. Trata-se de atividade disputadíssima em toda a sociedade, um território pelo qual distintos grupos sociais se enfrentam. É coisa de quem tem muito o que fazer, dos que desejam promover ou influenciar a produção da identidade de um grupo social. Nos palcos, estádios, praças e ruas, a festa é sempre uma arena onde se desenrola uma ação coletiva especial, na qual uma comunidade dispersa, heterogênea e dividida se expressa como um grande sentido de unidade e comunhão.

A festa e seus elementos, como a música, são extremamente importantes para a relação entre o homem e o meio, pois essas manifestações sempre refletiram o modo como os grupos sociais pensam, percebem e concebem seu meio ambiente, valorizam mais ou menos certos lugares. Claval $(1995: 6,7)$ nos recorda que o homem não habita apenas num mundo construído por água, pedra e ferro, já que o espaço social também é formado por representações, palavras, discursos, imagens, símbolos e rituais que dão vida e sentido aos lugares e comunidades.

Clarence Glacken $(1996: 117,118)$ mostrou que tal percepção é muito antiga, ao comparar as contribuições de Aristóteles e Políbio (séc. II a.C.) para as idéias sobre o meio ambiente no pensamento ocidental. Políbio teria sido mais original que Aristóteles porque além de reconhecer a importância do meio físico para a dinâmica social, igualmente valorizou o meio cultural. Em Políbio Glacken encontrou "a primeira exposição completa da idéia de que um meio físico produz um certo tipo de caráter étnico, e que este pode ser contra-arrestado mediante um trabalho consciente, intencional e árduo levado a cabo por instituições culturais (como a música)..." 
Ao descrever o povo de Arcádia, que vivia "um modo de vida austero que era a consequiência de um clima frio e lôbrego", Políbio ressalta a boa reputação que os arcádios desfrutavam entre os gregos, especialmente por sua cordialidade para com os estrangeiros e a devoção religiosa. Sua música e seus torneios musicais lhes conferiam tal identidade. Na educação de suas crianças estas práticas eram permanentemente incentivadas, como uma necessidade distante de qualquer frivolidade, pois tinham a função de permitir a convivência com um meio ambiente reconhecidamente hostil.

Glacken afirma que este é um relato da passagem da barbárie - onde o meio imperava -, para a civilização, sendo esta o resultado da ação e decisão dos heróis da cultura; que tal concepção é similar àquela esposada pela historiografia moderna, para a qual a civilização equivale ao processo de domínio da natureza pelo homem. A diferença entre os relatos arcaicos e os modernos é que, para os primeiros, esta passagem era conduzida pelos esforços conscientes de seus heróis da cultura, os poetas e anciãos, enquanto para os modernos a civilização resulta dos inventos, da ciência e do saber tecnológico.

Podemos fazer aproximações e paralelos entre os arcádios e os grupos populares que fizeram as escolas de samba, para assim reconhecer que a historiografia muitas vezes se omite quanto à permanência dos heróis da cultura na sociedade moderna. As escolas de samba são instituições culturais que resultam de um árduo e persistente esforço guiado pela consciência e o discernimento de seus heróis, poetas e anciãos. Através da música, da dança e da representação estes grupos sociais contornaram a adversidade do meio ambiente a que foram reduzidos na metrópole, alcançando uma identidade e laços transcendentais com seu território. A música ali também é uma necessidade permanente, não é alienação, atavismo telúrico como quis Lamego, ou qualquer outro tipo de irracionalismo. Nada pode revelar melhor essa sensibilidade que o nome escola e, mais ainda, os versos de Nélson Cavaquinho e Guilherme de Brito no antológico samba "Folhas Secas":

Quando piso em folhas secas

Caídas de uma mangueira

Penso na minha escola

E nos poetas da minha Estação Primeira

Não sei quantas vezes

Subi o morro cantando

Sempre o sol me queimando

E assim vou me acabando

Quando o tempo avisar

Que eu não posso mais cantar

Sei que vou sentir saudades

Ao lado do meu violão

Da minha mocidade 
Muitos depoimentos dos sambistas pioneiros apontam que a fundação das escolas de samba melhorou o ambiente de suas comunidades, que eram no período entre as duas grandes guerras favelas recentes ou em formação, periferias e subúrbios pobres do Rio de Janeiro, carregados de estigmas, condenados ao desprezo, anonimato e muitas vezes à remoção. Com esta instituição, a favela, o subúrbio e a periferia deixaram de ser apenas o lugar da barbárie e conquistaram a civilização o direito à cidade como definiu Henri Lefebvre -, ou pelo menos, com elas já não se poderia afirmar que estes eram simplesmente territórios da selvageria e da incultura. Muitos desses bairros e favelas não se explicam ou não teriam permanecido sem os seus blocos e escolas de samba. Em 1934, por exemplo, os sete mil moradores do morro do Salgueiro abortaram na Justiça um processo de despejo, liderados pelo sambista e compositor Antenor Gargalhada, da Escola Azul e Branco, uma das escolas de samba que existiu naquele morro e que mais tarde deu origem aos Acadêmicos do Salgueiro (CABRAL:1996).

A história e a geografia das escolas de samba são parte de um relato do modo como certos grupos populares do Rio de Janeiro estabeleceram relações com seu espaço vivido e meio ambiente, os bairros populares, favelas e subúrbios. Foi especialmente através desta instituição que os grupos expulsos da cidade contra-arrestaram a marginalização e a segregação espacial, política e cultural que os desmoralizava, situação inerente ao processo de modernização urbana do Rio de Janeiro no século XX (FERNANDES, 1996). Com as escolas de samba esses grupos construíram e aperfeiçoaram o convívio comunitário, se reinterpretaram e conquistaram uma identidade na cidade. Identidade que muito rapidamente passou a ser não só a da cidade como da própria nação brasileira. Com isto, a história e a geografia das escolas de samba, além de revelarem as complexas relações que envolvem a cidade, a festa e a cultura popular, expõem um fato raro, em que os vencidos, ao menos no plano da cultura, foram vencedores.

\section{A CIDADE, A FESTA E A CULTURA POPULAR}

Resumo: Na tradição dos estudos urbanos a festa e o ritual foram um tema esquecido pelos geógrafos. O presente artigo procura situar as razões teóricas e epistemológicas para tal "esquecimento", fundamentando as relações necessárias e arquetípicas entre a cidade e a festa. Procura-se também recuperar alguns princípios conceituais sobre a festa e a sua importância para as relações entre os grupos sociais, seu espaço e a construção de suas identidades, destacando-se o caso das escolas de samba do Rio de Janeiro.

Palavras-chave: cidade, festa, identidade social

\section{CITY, PARTY AND POPULAR CULTURE}

Abstract: Feast and ritual as a theme for research have been overlooked by geographers in the urban studies tradition. This article aims to point out the theoretical and epistemological reasons for this "forgetting", stating the necessary and archetypical relationships between the city and the feast. This study also recovers some conceptual principles about feast 
and its significance to the relationships among the social groups, their space and the building of their identities, highlighting the case of Samba Schools in Rio de Janeiro.

Keywords: city, feast, social identity

\section{BIBLIOGRAFIA}

BAKHTIN, M. (1971). La cultura popular en la Edad Media y en el Renacimiento. Barcelona: Barral Editores.

CABRAL, S. (1996). As escolas de samba do Rio de Janeiro. Rio de Janeiro:Lumiar.

CALVO, E. G. (1991). Estado de fiesta. Madri: Espasa Calpe.

CAPEL, H. (1981). Filosofia y ciencia en la Geografia contemporánea. Una introducción a la Geografia. Barcelona: Barcanova.

CLAVAL, P. (1981). Les geographes et les realités culturelles. L'Espace géographique v. 10

(1987). Geografia Humana y Economica Contemporánea. Madri: Eds. Akal.

FERNANDES, N. N. (1996). O "rapto ideológico" da categoria subúrbio. Rio de Janeiro (1858-1945), Tese de Mestrado. Rio de Janeiro: PPGG-UFRJ.

.(1999). O samba em "O Homem e a Guanabara". I Encontro Nacional de História do Pensamento Geográfico, Eixos Temáticos. Rio Claro: UNESP ICGE, v. 1.

. (2001) Escolas de Samba: sujeitos celebrantes e objetos celebrados. Rio de Janeiro: Prefeitura da Cidade do Rio de Janeiro/ Arquivo Geral da Cidade do Rio de Janeiro.

GLACKEN, C. J. (1996). Huellas en la playa de Rodas. Naturaleza y cultura en el pensamiento occidental desde la Antiguedad hasta finales del siglo XXVIII. Barcelona: Ediciones del Serbal.

LAMEGO, A. R. (1964). O homem e a Guanabara. Rio de Janeiro: IBGE-CNG.

LEFEBVRE, H. (1991). O Direito à Cidade. São Paulo: Editora Morais.

MAQUARD, O. (1998). Pequeña filosofia de la fiesta, In. Schultz, U. (org.) $L a$ Fiesta. Una historia cultural desde la Antiguedad hasta nuestros dias. Barcelona: Altaya.

MONBEIG, P. (1943). O estudo geográfico das cidades. Boletim Geográfico. CNG-IBGE, ano $1, n^{\circ} 7$

MUMFORD, L. (1982). A cidade na história: suas origens, desenvolvimento e Perspectivas. São Paulo: Martins Fontes.

VIANNA, H. (1995). O mistério do samba. Rio de Janeiro: Jorge Zahar Editor/Editora UFRJ. 